few entrepreneurs took advantage of the stock markets to raise capital. Bui by 1850 , industry had corne to need more capital, and it became much more difficult for the artisan to set up business on his own. At the same time, science caught up with engineering, and began to capture some of the prestige which it still retains. The educational system failed to adapt, and by concentrating on the production of administrators ensured that the prestige of engineering was further depressed. Finally, the decline of Britain had a hint of inevitability about it, once the ideas to which it had given birth had been absorbed by countries better supplied with natural resources. Even before the Great Exhibition, The Economist had been warning that "the superiority of the United States to England is ultimately as certain as the next eclipse". Perhaps we ought to be surprised that it took as long as it did for this prediction to come true.

L. T. C. Rolt describes the achievements of the Victorians, and their ultimate failure, with all his eustomary skill. On this subject nobody writes better, and this latest book deserves a place on the bookshelf alongside his biographies of tho giants of Victorian engineering.

Nigel Hawkes

\section{ROCK DATING}

\section{Potassium-Argon Dating}

Principles, Techniques and Applications to Geochronology. By G. Brent Dalrymple and Marvin A. Lanphere. (Series of Books in Geology.) Pp. xiv +258. (W. H. Freeman: San Francisco and Folkestone, February 1970.) $70 \mathrm{~s}$.

PotassIUM-ARGON dating of ancient rocks and minerals is one of the most powerful means of investigating the past at present available to Earth sciontists. Because potassium is the soventh most abundant element in the Earth's crust and is found in most rock-forming minerals, the method is of almost universal application to geological material. In practice, however, potassium-argon geochronometry does not always reveal the initial age of crystallization, and for various reasons the apparent age obtained may be related to other events in the geological history of the rock or mineral boing dated. In addition, it is an expensive analytical technique that requires a highly specialized laboratory and specially trained research staff.

As a geological tool, potassium-argon radio age analysis is used in four principal ways: (1) age assignment and correlation; (2) dating of past episodes of magmatism, metamorphism, tectonism or metasomatism; (3) evaluation of the rates of geological processes; and (4) as an indicator of past geological conditions. Interpretation and the application of the analytical results of potassiumargon dating to the solution of geological problems require a considerable first-hand knowledge of many scientific disciplines and for these reasons potassium-argon geochronology is necessarily a team science. The authors of this book, Brent Dalrymple and Marvin Lanphere, are research geologists with the United States Geological Survey at Menlo Park, California. Between them they have a wide interdisciplinary experience and belong to one of the most successful potassium-argon dating teams.

Radiogenic argon-40 was identified in old minerals for the first time in 1948 and attempts at potassium-argon dating of rocks and minerals began immediately. By the mid-1950s early results were beginning to influence geological research and over the past decade an ever increasing volume of potassium-argon age determination studies has led to some spectacular advances in the Earth sciences. Over the period of rapid expansion and development the numerous advantages and the limitations of the method have become apparent to workers in the field, but this detailed knowledge has not always been available to Earth scientists generally. In this excellent review, the authors have succeeded in describing the scientific background, theory, analytical techniques, accuracy, precision and geological application of potassium-argon dating in a very succinct and eminently readable way. The book will be invaluable to nonspecialist geologists wishing to understand and utilize the results of potassium-argon age determination and, because it is the first completely balanced text on the subject, it will be of considerable interest to research geochronologists already familiar with the method.

In any rapidly evolving science, research will overtake descriptive textbooks almost as soon as they are published. New ${ }^{40} \mathrm{Ar} /{ }^{39} \mathrm{Ar}$ analytical techniques have already vastly extended the range of potassium-argon dating over that of the conventional method described by Dalrymple and Lanphere. The 1970 s will undoubtably see further dramatic advances.

Frank J. Fitch

\section{SURFACE PROPERTIES}

\section{Solid State Surface Science}

Vol. 1. Edited by Mino Green. Pp. xii +420. (Delkker: New York, October 1969.) \$18.50; 176s.

EDITors of scientific journals have been recently accused of forcing some unwilling scientists to adopt SI units; it is possible that the title of this volume may in future be quoted as an example of the dire consequences of succumbing to the exhortations of editors for conciseness ! Certainly the title will puzzle many prospective purchasers as to its contents; and the reviewer, by use of these four nouns together with necessary hyphens and soliduses, has also failed to invent an alternative title that makes scientific sense! It is therefore necessary to state that this volume, the first of a series on similar topics, is concerned with the fundamental aspects of the properties of the surface and boundary regions of solids.

The first ehapter, by Juro Horiuti and Tomiyuki Toya, is eoncerned with the perturbation of the electronic configuration of an infinite perfect crystal by the creation of a surface, and the modifications caused by lattico vacancies and emergence of dislocations. The properties of hydrogen chemisorbed on both metals and semiconductors (isotherms, differential adsorptions, entropy, infrared spectra) are discussed in this context as is the accompanying change of the electrical conductivity of metal films. Considerable emphasis is placed on the authors' views on the existence of differently located $r$ and $s$ hydrogen adatoms. It is a scholarly article of high quality, but requires considerable effort on the part of the reader.

The sceond chapter, by R. F. Greene, is largely con. cerned with transport phenomena in which electrons remain bound and are close to the surface-again, an extremely good and concise account. Research workers concerned with surface-related electronic phenomena such as size effects, anomalous skin effects and field effects in semiconductors, and the like, will certainly find much of interest and value.

The third chapter, by Mino Green and M. J. Lee, is largely an account of Green's contribution to the problem of covalent, electrostatic and charge transfer adsorption complexes. The treatment is semi-empirical in nature and therefore is less demanding on the reader; although a useful chapter, it lacks the depth and penetration of the preceding two chapters.

The fourth chapter, by J. C. Rivière, is a critical review of the methods used for the measurement of work functions and the results obtained. The theory associated with the various methods is outlined, and results for metal alloys and binary metal compounds are tabulated and appraised. This is a timely and comprehensive article. 